\title{
Inverted Classroom by Topic - A Study in Mathematics for Electrical Engineering Students
}

\author{
http://dx.doi.org/10.3991/ijep.v4i3.3299 \\ I. Braun, S. Ritter and M. Vasko \\ Karlsruhe University of Applied Sciences, Karlsruhe, Germany
}

\begin{abstract}
The inverted classroom is a teaching model, where the students prepare for classroom by watching video lectures. The classroom time is then dedicated to individual practice. We evaluated a mathematics course for electrical engineering students throughout three semesters, where $20 \%$ of the topics were taught using the inverted classroom model. The aim was to find out whether the model can help to better address groups with large differences in prior knowledge in mathematics. We report mainly positive feedback from the students, although the opinions vary greatly between the groups. The students appreciate the increased amount of practice in the classroom as well as the possibility to learn at their own pace. Exam performance remained constant in the topics taught using the inverted classroom compared to previous semesters. The exam performance of weaker students also remained constant.
\end{abstract}

Index Terms-inverted classroom, flipped class, mathematics.

\section{INTRODUCTION}

\section{A. The Challenges}

Mathematics is a central skill for engineering students and the skills acquired during the first-year mathematics courses are later required in many higher level classes. Studies also reveal that the mathematics grades of engineering students strongly correlate with their later academic success [1].

At the same time mathematics courses present a major hindrance for many engineering students. At universities of applied sciences in Germany it is not unusual for $40 \%$ to $60 \%$ of the students to fail a mathematics exam. Failed mathematics exams are also one of the main reasons for university dropouts.

One of the major challenges the faculty in universities of applied sciences in Germany faces are the great differences in the first year students' prior knowledge in mathematics. This derives partly from the opening of the universities of applied sciences for students who do not have a high-school degree (Gymnasium), but have instead completed a vocational school supported by appropriate working experience. Differences exist not only in the skill levels of the students but also in the topics they have been taught in school [2] [3]. Linear algebra, for example, is a topic where some students already have solid skills, whereas others have never heard the topic in school.

Further issue is the lack of continuous independent study and practice during the semester, especially among the first year students. In most mathematics courses exercises are voluntary and are usually not graded.
Studies conducted in German universities reveal that students rarely prepare for classes beforehand or recap the content directly after the class. Furthermore, although the students regularly attend the lectures, they often underestimate the difficulty of the subject and the effort required to pass an exam. Active independent study and practice often starts only shortly before the exam [4].

\section{B. Traditional Lecture}

The most common way of teaching, the lecture, gives little time or tools for supporting heterogeneous groups. Furthermore there is reason to believe that the reported problems are intrinsic to a teaching style using the traditional lecture and should not be blamed solely on the students.

First of all, lectures proceed at the pace set by the instructor that all students are supposed to follow. Lectures have been described as the "one-size-fits-all" model of instruction, where every student receives the same instruction [5]. This model implicitly expects all students to begin on the same knowledge level. There is neither time nor the possibility to support students with gaps in their prior knowledge. Missing information - due to forgotten knowledge from school or a temporary slip of attention - will immediately affect understanding for the rest of the section. Even very good students suffer from this when the thread of reasoning is lost by thoughts wandering off in unchallenged times.

Second, the instructor gets no reliable feedback on the actual student learning during the semester. In German universities of applied sciences (in contrast to research universities) there is usually no culture of mid-term exams or graded homework due to lack of staff. The common practice of developing the lecture through (leading) questions leads the students and the instructor to perceive a potentially dangerous illusion of understanding. A recent study finds that a well-presented lecture gives the student an illusion of having understood the discussed topics [6]. This seems to be the case for those students, who reported that although they regularly attended the classes they still underestimated the difficulty of the topic.

Finally, students usually practice alone, or sometimes in study groups or in guided exercise sessions offered by tutors. The instructor is, however, usually not present during the exercise. This presents difficulties especially when applying knowledge to practical engineering problems, where the support from an expert would be required. Failure in solving the exercise problems may result in a negative self-image and lower motivation [7].

These points may indicate a connection between the issues mentioned above and the way of teaching, since the 
lecture is by far the most common method used by faculty at many universities of applied sciences, especially in introductory courses.

\section{The Inverted Classroom Model}

The inverted classroom (IC), or the flipped class, is a teaching model, where the students prepare for the classroom by watching video lectures at home, whereas the classroom time is dedicated to practice, problem solving, discussion, and individual support to the students [8].

Although the inverted classroom has received relatively high attention in the media, there is so far little rigorous empirical research on the model [9] [5]. As noted by [5], the inverted classroom model is related to other teaching strategies involving interactive engagement, such as active learning or peer instruction. One could thus expect learning gains, such as those reported by [10] and [11], also from inverted classroom.

Thus the inverted classroom is a promising teaching method to address the issues presented above, since it gives the instructor more freedom in arranging the classroom session. There are reports on the positive effects of the flipped class in mathematics courses [12]. There is also some evidence that the inverted classroom setting can help to address heterogeneous groups [13].

The inverted classroom starts from three basic assumptions:

1. Class time is valuable! In fact, it is so valuable it should be spent with maximum engagement from the students.

2. Direct instruction through lecture is effective for presentation of knowledge, but it loses little from videotaping.

3. Instruction has to precede application.

As a consequence, instructors using the inverted classroom offer their students prerecorded video lectures, which the students should watch as preparation for the class. This allows for a self-paced preparation with the options to "pause and rewind" or to use additional resources to cover missing basics when needed. As a consequence, the differences in knowledge should decrease, because students have a chance to identify and eliminate their gaps before coming to class.

In class, the focus shifts from content presentation to deepening student understanding, problem solving, discussion or other student-centered activities. The presence of the instructor and support from peers during this vital phase of learning helps to quickly identify and address misconceptions and may ultimately even save time for the students. Reference [14] reports that students do not spend more time studying for an IC course compared to time used for traditional lectures.

Furthermore, the instructor has the possibility to follow the progress of individual students and thus receive a more thorough view of the current skill level in her class.

A visualization comparing the learning sequence of IC with traditional lectures is shown in Fig. 1. A good summary of the method and previous studies can be found in [5] [9].
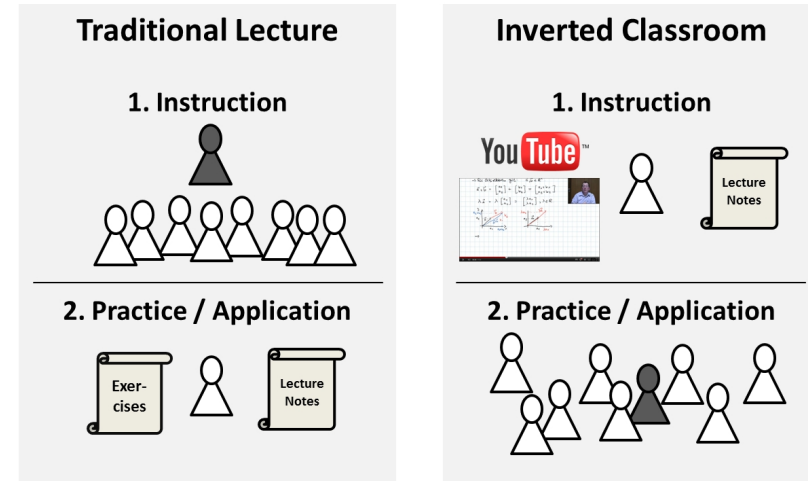

Figure 1. Inverted Classroom. The classroom time changes its role from instruction to practice and application. Individual study takes place before class using prerecorded lecture videos, possibly supplemented by reading materials [15].

\section{The Study SetTing}

\section{A. The Research Questions}

The aim of this study is to evaluate the suitability of the inverted classroom model for mathematics courses in a university of applied sciences. We will discuss the following main research questions:

1. How do students perceive and evaluate the new model?

2. Can the learning objectives of a mathematics course for engineering students be achieved with the inverted classroom method?

3. Can the inverted classroom help to address heterogeneous groups better than traditional lectures?

\section{B. The Course and the Learning Objectives}

The study focuses on a mathematics course (Course I) taught during the first-semester of the bachelor's degree programs Electrical Engineering - Information Technology and Electrical Engineering - Industrial Automation at the Karlsruhe University of Applied Sciences. For comparison the inverted classroom model was also tested in a third-semester mathematics course (Course III) of the same degree programs.

The Learning objectives for Course I are defined as:

- Acquiring basic knowledge in mathematics

- Acquiring proficiency in calculations

- Application of the knowledge to practical problems

Before the onset of this study, the course with typically 50-70 students was taught utilizing an instructor-centered but interactive lecture format using (leading) questions. It included worked examples and computer simulations as well as short periods of individual or group problem solving. Exercise problems with answers were provided but not controlled. Exercise was expected to be done outside the classroom.

\section{Topic Selection}

Instead of inverting the complete course we decided to pick selected topics for inverting. The reason for this was to give the students the possibility to compare IC with the traditional lectures. There are two types of topics we consider especially suited to be taught with the inverted classroom model: 
1. Topics where students have large difference in prior knowledge. A traditional lecture on such topic would either bore or overburden most participants. This was the reason for choosing the topics "functions" and "vectors" in Course I.

2. Topics requiring a large amount of non-trivial practice. In such topics the presence of an instructor during this practice can further understanding, avoid frustration and ultimately save time for the student: This consideration led us to the topic "systems of differential equations" in Course III.

\section{Course Statistics}

In Course I the topic "functions" was covered in 3 sessions of 90 min each. 14 short videos were produced for the topic with the total duration of 183 minutes. The topic "vectors" was also covered in 3 sessions. The video material for "vectors" covered 143 minutes. Altogether circa $20 \%$ of the course was taught using the inverted classroom model.

The study was conducted in Course I during the following semesters:

- Summer semester of 2012: 55 students enrolled, 34-45 participated in the inverted classroom sessions, 44 answered the questionnaire

- Winter semester of 2012/2013: 62 students enrolled, 30-35 participants, 30 answered the questionnaire

- Summer semester of 2013: 73 students enrolled, 30-40 participants, 36 answered the questionnaire

The students' average age varies between 21.7 and 22.0 years. The classes had only $6 \%$ to $10 \%$ female students, which is not sufficient to discuss gender differences in the perception of the method.

In Course III the topic "systems of differential equations" was covered in 3 sessions of 90 minutes each. The video material included 10 videos with total duration of 137 minutes. Altogether circa $10 \%$ of the course was taught using the inverted classroom. The inverted classroom model was tested in the summer semester of 2012. 19 students were enrolled in the course, 17 participated in the inverted classroom sessions with 15 answering the questionnaire.

\section{E. Implementation of the Model}

A motivational introduction to prepare the students for the concept was given in advance. Students agreed with the general goals and the idea of increased practice.

Pre-Class Activities: The videos were screencasts of a tablet computer, recorded with Camtasia Studio 7 and supplemented with an inset video image of the instructor. They were cut to 5-30 min length and distributed in HD via YouTube (http://www.youtube.com/projektskating) using links from the learning management system. The videos were cut so that each video included one coherent topic. Voluntary guiding questions were offered to the students in the learning management system to ensure active listening.

In-Class Activities: Classes usually started with an introductory discussion presenting both possible problems and the guiding questions. The main part of the session was spent solving practical exercise problems at a typical homework level. Students either chose to work individually or teamed up with their neighbors, while the professor went around offering support where it was welcome and needed. When most students had completed the tasks, a volunteer presented the solution on the blackboard.

\section{F. The Research Method}

The experiment involved evaluations on different levels: a subjective report from the instructor, a voluntary paper and pencil questionnaire offered to the students and an analysis of exam performance.

In addition to the report of the instructor, the in-class activities were documented by an independent observer. The observer attended both the inverted classroom and traditional classroom sessions. This was necessary to perceive the concrete changes between the teaching methods.

In order to evaluate the students' opinion of the inverted classroom model, an anonymous paper and pencil evaluation was conducted shortly after the inverted topics had been completed. Since only two topics were inverted, the students were in a position to compare the inverted classroom with the traditional lecture. The 6-page questionnaire included questions on the videos and their use, on the classroom session, a comparison between the traditional lecture and the inverted classroom, as well as on overall opinion of the teaching model.

We analyzed total six semesters of exam performance of the students: three semesters taught entirely in the traditional lecture style and three semesters, which included the inverted classroom sessions. All courses were taught by the same instructor. Since inverted classroom covered only two topics, it was necessary to look into the students' performance in solving individual exam questions related to these topics.

\section{RESULtS}

\section{A. Instructor's Opinion}

For the instructor, the inverted classroom model provides a possibility to support students individually. Support and help can be given exactly at the stage where it is required by each student. Furthermore, increased interaction and discussion in the classroom, as well as coaching of individual students, gives the instructor valuable feedback on the level of understanding and the learning process of individual students in the class. This is a major advantage compared to traditional lectures, where the instructor receives proper feedback only in the final exams, after the course has already finished.

Due to diversified use of lecture time instead of repeating similar monologue each semester, the course becomes livelier for both the students and the instructor. We observed that in the sessions taught using the inverted classroom the instructor spend approximately $40 \%$ of the time explaining, the other $60 \%$ of the time being used for individual practice. This is a significant change compared to the traditional lectures, where $75 \%$ of the time was used by the instructor in presenting the content.

In the summer semester of 2012 in Course I the instructor, instead of dedicating the time for practice, presented additional computer simulations or applications, so that the inverted classroom was in part turned back into a traditional lecture. Based on our experience and the feedback from the students, we recommend not using 
inverted classroom as a means for squeezing in additional content.

The major dilemma for the instructor was how to deal with students who had not watched the videos beforehand, usually circa $20 \%$ to $25 \%$ of the students. On the one hand, too much recap would demotivate the other students, who had prepared themselves for the class. On the other hand, those students, who did not have a possibility to watch the videos, would be unable to work in the classroom session.

The effort to produce videos for the inverted classroom is significant but bearable. Support in video editing is, however, highly recommended.

\section{B. Students' Opinions}

The evaluation was conducted during three semesters with 110 students who attended Course I.

Videos: Overall satisfaction on the videos was positive with $81 \%$ of the students rating the quality of the videos "good" or "excellent". The students were also satisfied with the plain design of the videos, without fancy animations or graphics. While $19 \%$ would like to see more graphics or animations, others wrote that animations would only distract them from the subject matter. $15 \%$ of the students complained that the videos were too long.

The students also appreciated the possibility to learn at their own pace and to watch the videos several times if necessary. $56 \%$ of the students replayed video sequences occasionally or often, the main reason mentioned being difficulty to understand the content. $78 \%$ stated that they had more control on their individual learning process compared to the traditional lectures. Some students wrote that they did not watch the videos, because they already knew the topics from school.

When asked to compare the learning from the videos with learning in a traditional lecture the opinions were divided. Most students, however, said that through videos they learned neither better nor worse than in a lecture. However, $80 \%$ of the students agreed that they were well prepared for the classroom session after watching the videos. One student even wrote that it is now easier to cover content, which he/she did not have in school. These statements support the idea that diverse learners can be addressed and supported better with the inverted classroom model than in traditional lectures.

Classroom Session: The classroom session received also positive evaluation with $80 \%$ of the students agreeing that the interactive classroom session was "fun". The students also felt that their individual pace of learning was better taken into account than in traditional lectures. The students also felt that they received more feedback than during traditional lectures.

The students also found it positive that there was more time to practice in the classroom and many listed this as a major advantage of the inverted classroom model compared to traditional lectures. This may seem puzzling to some instructors, as the students traditionally can and should practice at home at their own pace. Studies on homework, however, reveal that the presence of the instructor during practicing is very important, especially when learning complex topics. Practice without immediate support can quickly lead to frustration [7].

Overall perception: Although the students recognized these positive effects of the inverted classroom model they still did not see overall benefits in learning, nor did they feel better prepared for the exam than in other topics. Questions related to learning results received only moderately positive answers.

When asked, which model the students prefer, only $40 \%$ preferred the inverted classroom, whereas $37 \%$ said they prefer the traditional lecture, the remaining students were not yet able to decide between the two models. There were also huge differences between the different semesters, as shown in Figure 2. For example in the summer semester of $201251 \%$ preferred the inverted classroom and only $18 \%$ the traditional lecture. In the summer semester of 2013 the number interchanged to only $23 \%$ preferring the inverted classroom and $56 \%$ preferring the traditional lecture. This indicates that group dynamics could have major influence on the success of the inverted classroom model.

When asked what percentage of a course should be inverted most students answered that the inverted classroom should not be used exclusively (see Figure 3). Furthermore, in the open questions some students wrote that in their opinion the inverted classroom is not suited for all topics or all courses.

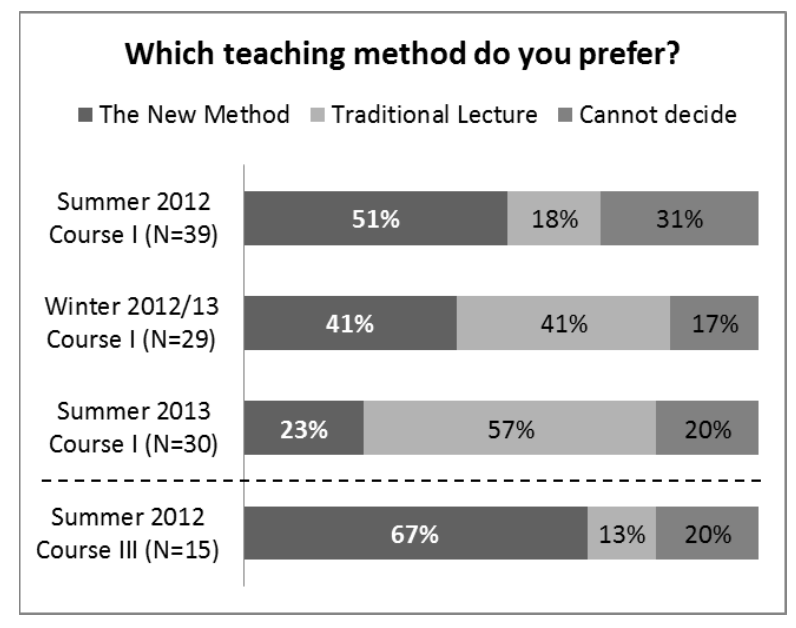

Figure 2. The figure shows the high variation between the cohorts in their opinion on the inverted classroom. The original question was "Alles in allem, welche Form der Veranstaltungsgestaltung würden Sie bevorzugen?" and the answer possibilities „Die neue Methode“, „Klassische Vorlesungen“, and „Kann ich noch nicht beurteilen“.

\section{What percentage of the course should be taught using the inverted classroom?} $(\mathrm{N}=88)$

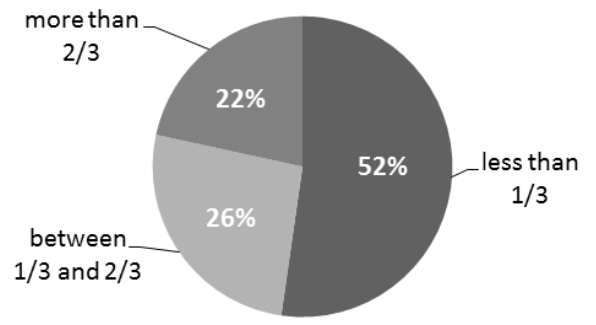

Figure 3. More than half of the students think that less than $1 / 3$ of a course should be taught using the inverted classroom. This was an open question with the original title "Welcher Anteil einer Lehrveranstaltung innerhalb eines Semesters sollte in dieser neuen Form durchgeführt werden $(0 \%$ bis $100 \%)$ ?“ 
Other negative aspects mentioned by the students were the workload required when preparing for the classroom sessions, as well as the fact that if you do not have time to watch the videos, the classroom session is useless.

$3^{\text {rd }}$ Semester: The questionnaire was completed by 15 students who attended Course III. It is worth noting that the third semester students in Course III evaluated the model better in all aspects than the first semester groups. Of these students $67 \%$ prefer the inverted classroom, whereas only $13 \%$ found the traditional lecture better (see Figure 3). The reasons for this could lie in the group size. With 50 students in Course I compared to 20 in Course III the instructor was able to give more individual guidance to each student. Further reasons could be the "maturity" of the students in the third semester, who see the benefits of continuous practice, or the reduced heterogeneity of the group; only the "better" students have passed the exams in the first two semesters. Furthermore, the different reason for the topic selection can play a role in student satisfaction. Further research would be required to find out the suitability of the inverted classroom for different groups and students.

\section{Student Workload}

Students report an increase of the total workload of inverted classroom compared to the traditional lecture. $77 \%$ of the students said that they invested more time on preparation than usually and $37 \%$ of the students explicitly complained in an open text question that they either needed to invest more time than for traditional lectures or that they did not have the time to watch the videos. However, circa $80 \%$ of the students who attended the classroom sessions said that they had watched the videos beforehand.

The questionnaire included a question asking for the amount of time required for the inverted section and the amount of time students thought they would have used on that specific topic in a traditional lecture. On average students in Course I report an increase of 0.9 hours in workload per week due to the inverted classroom (average 7.3 hours instead of 6.4 hours per week). The maximum time reported for the IC model was 15 hours per week. The times include 4.5 hours of lecture time each week and an average of 2.7 hours videos per week for the inverted classroom sessions.

Almost half of the students (45\%) said that the time they invested was profitable for learning (only $18 \%$ said it wasn't, the rest could not decide before the final exam), and $67 \%$ agree that the effort and learning results were balanced.

It should be noted that the course demands 90 hours of self-study over the semester. We have to assume that most of this occurs close to the final exam, as shown by [4]. If we attribute 30 hours to end-of-term studying, students would still have to spend $4 \mathrm{~h}$ per week with self-study. Even with the reported increase due to the videos, no course reached these times. These numbers are selfreported, the validity is to be questioned, and according to [4] the actual values could be even lower than the perceived ones.

We conclude that although the students complain about the additional workload, it is still in agreement with the course requirements (6 ECTS-credits with 90 hours lectures and 90 hours independent study). When using the inverted classroom, there is no reason for changing the course structure or adding the required off-class learning time.

\section{Learning Gains}

To study the influence of the inverted classroom model on the problem solving ability of the students we analyzed the exam results of three semesters with the inverted classroom (total 147 exams) and three preceding semesters without the inverted classroom (total 116 exams). The students who repeated the exam for $2^{\text {nd }}$ or $3^{\text {rd }}$ time were excluded, as we cannot assume that they attended the classes during the following semesters.

Each exam included six questions and the topics tested remained unchanged throughout the period of study. The aim of the instructor was also to keep the difficulty level of the questions constant throughout the semesters. Yet, to compensate for possible differences in the difficulty of the exams and the random variation in the ability level of the students, we combined the results of three semesters with the intervention into an experimental group and the preceding three semesters without the intervention into a control group.

Of the two topics taught using the inverted classroom, the topic "vectors" was tested in a separate exam question throughout all exams, while the other topic, "functions", was tested implicitly in several questions. We therefore decided to use the score on the "vector" question, varying from 0 to 4 , as the experimental variable.

Overall, there were no significant differences in the exam performance for the "vector" question between the two groups, $t(261)=0.145, p>.05$. The mean score the students earned from the question remained constant $(\mathrm{M}=1.21, \mathrm{SD}=1.34$ in the experimental group, $\mathrm{M}=1.23$, $\mathrm{SD}=1.37$ in the control group). The overall exam performance also remained constant throughout the period.

We also analyzed the performance of the quartile of students with the highest total score and the quartile of students with the lowest total score, excluding the "vector" question in both cases. This was done in order to find out whether weaker students would profit from the inverted classroom.

When comparing the quartile of students with the lowest total score in the experimental group and the control group we found no significant differences in the performance for the "vector" question (see Figure 4), $\mathrm{t}(64)=0.363, \mathrm{p}>.05$. However, among the quartile of students with the highest total score the performance for the "vector" question was for the experimental group $(\mathrm{N}=37, \mathrm{M}=2.65, \mathrm{SD}=1.16)$ higher than for the control group, $(\mathrm{N}=29, \mathrm{M}=2.21, \mathrm{SD}=1.50)$, though the difference is not statistically significant, $\mathrm{t}(64)=1.35, \mathrm{p}>.05$.

We can conclude that although the exam performance of the whole group remained constant throughout the studied period, the results give us hint of "Matthew effect", i.e. "good" students might benefit more from the inverted classroom model. 


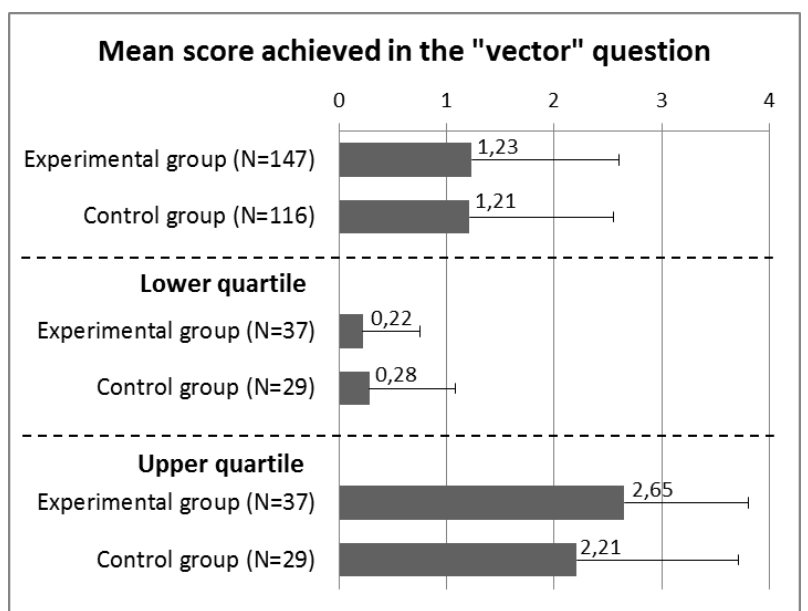

Figure 4. The mean score achieved in the "vector" question. Both the experimental group and control group include the exams from three different semesters. The lower quartile includes the students with lowest total score in the exam, the upper quartile the students with the highest total score (excluding the "vector" question)

\section{CONCLUSIONS}

We can conclude that the students in general have a positive view of the inverted classroom model. They especially appreciate the increased time for exercise during the classroom session and that they can learn at their own pace while watching the videos or practicing in the classroom.

It must be noted, however, that the acceptance of the inverted classroom varied significantly from semester to semester. In one semester we observed a group of students, circa one third of the class, strongly opposing the new model in favor of traditional lectures. The new model runs counter to their expectations; they see traditional lectures as an effective way of learning and as a fundamental part of university studies.

Reference [14] also reports such initial resistance, but adds that the students adjusted after a few weeks. He concludes that "the format should be implemented for an entire term in order to obtain full benefits of this approach" [14]. This is, however, in contradiction with the students' view, which states that the approach should not be used exclusively and is not necessarily suitable for all topics. We can conclude that class dynamics play a critical role in the acceptance of the inverted classroom model.

The most common negative aspect of the inverted classroom model mentioned by the students was higher workload. The total reported time the students used for the inverted topics, however, is still lower than the expected workload for the course. Furthermore, most students agreed that the increased time was beneficial for learning. Thus the critic on the workload seems unfounded.

We perceive no increase in exam performance through the inverted classroom model. It is possible that the intervention, which covered circa $20 \%$ of the course, was not large enough for the results to be visible in the exams. The study, however, confirms that the students' performance in general does not suffer from the inverted classroom model. Therefore, it would be possible to test the model in a complete semester.

Student motivation remains a critical component of the inverted classroom. Several students recognized as a disadvantage of the model, that if one does not watch the videos beforehand, the classroom session is useless. Such students can actually suffer from the new model.

Furthermore, the exam performance hints that "good" students might profit more from the inverted classroom model than weaker students. Therefore, the method can lead to a "Matthew effect", implying that the motivated students who are more likely to prepare for the class gain more during the interactive sessions. Students with a low interest in the topic or many other obligations have a higher probability of skipping the videos and thus will not benefit at all from the classroom sessions. At best, the divide now acts on the dimension of diligence instead of schooling. It is possible that this distinction is related to the findings reported by [16]: "inexperienced learners tended to benefit from more guided instruction."

Further research would be required to find out effects of the inverted classroom model on different student groups, including the differences between students with good or weak prior knowledge, as well as differences between first semester and higher semester students.

\section{REFERENCES}

[1] B. Hell, M. Linsner, G. Kurz, "Studienverlaufsuntersuchungen an der Hochschule Esslingen. Teil 2: Prognose des Studienerfolgs," in Studieneignung und Studierendenauswahl - Untersuchungen und Erfahrungsberichte, Report 42 - Beiträge zur Hochschuldidaktik, M. Rentschler and H.-P. Voss, Eds. Aachen: Shaker Verlag, 2008, pp. 132-178.

[2] U. Heublein, C. Hutzsch, J. Schreiber, D. Sommer, and G. Besuch, „Ursachen des Studienabbruchs in Bachelor- und in herkömmlichen Studiengängen“. Ergebnisse einer bundesweiten Befragung von Exmatrikulierten des Studienjahres, 8, 2007.

[3] K. Dürrschnabel, H.-D. Klein, C. Niederdrenk-Felgner, R. Dürr, B. Weber, and R. Wurth, Mindestanforderungskatalog Mathematik der Hochschulen Baden-Württembergs für ein Studium von MINT oder Wirtschaftsfächern (WiMINT). Ergebnis einer Fachtagung am 5. Juli 2012 in Esslingen. 2013. http://www.hochschuldidaktik.net/documents public/mak2013020 1.pdf

[4] R. Schulmeister, and C. Metzger, C., „Die Workload im Bachelor: Ein empirisches Forschungsprojekt," in Die Workload im Bachelor: Zeitbudget und Studierverhalten. Eine empirische Studie, R. Schulmeister and C. Metzger, Eds. Münster: Waxmann, 2011, pp. 13-128.

[5] K. M. Arfstrom, N. Hamdan, K. McKnight, P. McKnight, A Review of Flipped Learning. Flipped Learning Network, 2013. http://www.flippedlearning.org/cms/lib07/VA01923112/Centricity /Domain/41/LitReview FlippedLearning.pdf

[6] S. K. Carpenter, M. M. Wilford, N.Kornell, and K. M. Mullaney, "Appearences can be deceiving: instructor fluency increases perceptions of learning without increasing actual learning," Psychonomic Bulletin \& Review, 04 May 2013. http://dx.doi.org/10.3758/s13423-013-0442-z

[7] J. A. C. Hattie, Visible Learning: A synthesis of over 800 metaanalyses relating to achievement. New York: Routledge, 2009.

[8] J. Bergmann, and A. Sams, Flip Your Classroom: Reach Every Student in Every Class Every Day. Alexandria, VA: International Society for Technology in Education, 2012.

[9] J. L. Bishop and M. A. Verleger, "The Flipped Classroom: A Survey of the Research," Proc. $120^{\text {th }}$ ASEE Annual Conference \& Exposition, Paper ID \#6219, June 2013. http://www.asee.org/public/conferences/20/papers/6219/download

[10] R. R. Hake, "Interactive-engagement vs traditional methods: A six.thousand-student survey of mechanics test data for introductory physics courses", American Journal of Physics, Vol 66, 1998, pp. 64-74. http://dx.doi.org/10.1119/1.18809

[11] C. H. Crouch, and E. Mazur, "Peer Instruction: Ten years of experience and results," American Journal of Physics, 69 (9), September 2001, pp. 970-977. http://dx.doi.org/10.1119/ 1.1374249 
[12] K. Fulton, "Inside the Flipped Classroom," The Journal, 04/11/2012. http://thejournal.com/articles/2012/04/11/the-flippedclassroom

[13] G. Green, "My View: Flipped classrooms give every student a chance to succeed," CNN Schools of Thought Blog, January 18th 2012. http://schoolsofthought.blogs.cnn.com/2012/01/18/myview-flipped-classrooms-give-every-student-a-chance-to-succeed/

[14] G. Mason, T. R. Shuman, and K. E. Cook, "Inverting (Flipping) Classrooms - Advantages and Challenges," Proc. $120^{\text {th }}$ ASEE Annual Conference \& Exposition, Paper ID \#7171, June 2013. http://www.asee.org/public/conferences/20/papers/7171/download

[15] C. Spannagel, ,Lernen mit Vorlesungsvideos in der umgedrehten Mathematikvorlesung,“ in DeLFI 2012 - Die 10. e-Learning Fachtagung Informatik der Gesellschaft für Informatik e.V., J. Desel, J. M. Haake, and C. Spannagel, Eds. Bonn: Köllen Druck+Verlag, 2012, pp. 225-236. http://www.phheidelberg.de/wp/spannagel/publications/Fischer_Spannagel_2012 .pdf

[16] S. Kalyuga, P. Chandler, J. Tuovinen and J. Sweller, "When Problem Solving is Superior to Studying Worked Examples," Journal of Educational Psychology, Vol. 93, No. 3, 2001, pp. 579588. http://dx.doi.org/10.1037/0022-0663.93.3.579

\section{AUTHORS}

S. Ritter is with the Faculty of Electrical Engineering and Information Technology, Karlsruhe University of Applied Sciences, Karlsruhe, Germany (e-mail: stefan.ritter@hs-karlsruhe.de).

I. Braun is with the Service-Center for Teaching and Learning/Project SKATING, Karlsruhe University of Applied Sciences, Karlsruhe, Germany (e-mail: isabel.braun@hs-karlsruhe.de).

M. Vasko is with the Service-Center for Teaching and Learning/Project SKATING, Karlsruhe University of Applied Sciences, Karlsruhe, Germany (e-mail: mikko.vasko@hs-karlsruhe.de).

This work was supported in part by the German Federal Ministry of Education and Research, support code 01PL11014. Submitted, October, 31, 2013. Published as resubmitted by the authors on June 13, 2014. 